\title{
PENGARUH RETURN ON ASSET (ROA), DEBT TO EQUITY RATIO (DER), DAN EARNING PER SHARE (EPS) TERHADAP HARGA SAHAM PERUSAHAAN PERTAMBANGAN (SEKTOR INDUSTRI BATUBARA) YANG TERDAFTAR DI BURSA EFEK INDONESIA (BEI) PADA TAHUN 2016-2018
}

\author{
Christhoper Erick \\ Program Studi Magister Manajemen Universitas Tarumanagara \\ christhopererick@gmail.com
}

Masuk : 31-05-2020, revisi : 25-06-2020 diterima untuk diterbitkan : 25-06-2020

\begin{abstract}
The purpose of this study was to determine the effect of Return on Assets, Debt to Equity Ratio, and Earning per Share on the share prices of coal mining companies listed on the Indonesia Stock Exchange for the period 2016-2018. This research sample consisted of 23 companies selected using the purposive sampling method with the 2016-2018 research period. The method for analyzing research questions is to use panel data statistical regression methods. The result found that Earning per Share partially had a significant effect on stock prices. While Return on Assets and Debt to Equity Ratio partially have no significant effect on stock prices. But Return on Assets, Debt to Equity Ratio, and Earning per Share together have an influence on the share price of coal mining companies.
\end{abstract}

Abstrak : Tujuan penelitian ini adalah untuk mengetahui pengaruh Return on Asset, Debt to Equity Ratio, dan Earning per Share terhadap harga saham perusahaan pertambangan batubara yang terdaftar di Bursa Efek Indonesia untuk periode 2016 hingga 2018. Sampel penelitian terdiri dari 23 perusahaan yang dipilih dengan menggunakan metode purposive sampling dengan periode penelitian 2016-2018. Metode untuk menganalisis pertanyaan penelitian adalah dengan menggunakan metode statistik regresi data panel. Hasil penelitian menemukan bahwa Earning per Share secara parsial berpengaruh signifikan terhadap harga saham. Sementara Return on Asset dan Debt to Equity Ratio secara parsial tidak berpengaruh signifikan terhadap harga saham. Namun Return on Asset, Debt to Equity Ratio, dan Earning per Share secara bersama-sama mempunyai pengaruh terhadap harga saham perusahaan pertambangan batubara.

Keywords : Stock Price, Return on Asset, Debt to Equity Ratio, Earning per Share

\section{PENDAHULUAN}

Salah satu faktor pendukung untuk kelangsungan suatu industri adalah tersedianya dana. Sumber dana murah dapat diperoleh oleh suatu industri dengan menjual saham kepada publik di pasar modal. Kondisi ini secara langsung akan mempengaruhi pada aktivitas di pasar modal selanjutnya menyebabkan naik turunnya jumlah permintaan dan penawaran di bursa dan pada akhirnya berdampak pada perubahan harga saham, sehingga keadaan tersebut tentunya harus selalu diwaspadai oleh para investor khususnya sektor pertambangan yang bergerak dibidang tambang batubara.

Sektor pertambangan merupakan sektor yang berperan cukup penting bagi perekonomian nasional karena sektor pertambangan menjadi sektor primer bagi banyak sektor. Hal itu karena banyak hasil yang diproduksi oleh sektor pertambangan juga diperlukan oleh sektor lain. Perubahan yang terjadi pada harga saham disektor ini tentunya merupakan dasar penting untuk mempelajari perilaku investor dalam membuat keputusan investasi di pasar saham. Fluktuasi harga saham industri pertambangan batubara ini menarik untuk dikaji lebih lanjut faktor 
penyebabnya. Dimana pada tahun 2016 harga-harga saham industri mulai merangkak naik setelah melewati masa-masa sulit.

Oleh karena itu, penelitian ini bertujuan untuk mengetahui pengaruh Return on Asset (ROA), Debt to Equity Ratio (DER) dan Earning per Share (EPS) terhadap harga saham yang terdaftar di Bursa Efek Indonesia untuk periode 2016-2018 baik secara parsial maupun bersama-sama.

\section{TINJAUAN PUSTAKA}

Menurut Amanda (2013) menyatakan harga saham terjadi akibat adanya mekanisme pasar, yakni permintaan dan penawaran di pasar modal. Apabila suatu saham mengalami kelebihan permintaan maka harga cenderung akan naik, sebaliknya jika suatu saham mengalami kelebihan penawaran, maka harga saham akan cenderung turun.

Egam et al., (2017) menyebutkan bahwa Return on Asset (ROA) merupakan rasio untuk menunjukkan seberapa kontribusi aset dalam menciptakan laba bersih. ROA yang tinggi akan menarik minat investor untuk menanamkan modalnya pada perusahaan karena dianggap perusahaan tersebut dapat menghasilkan laba yang tinggi dan pada akhirnya akan berdampak positif terhadap pergerakan harga saham yang akan mengalami kenaikan. Hal ini didukung oleh penelitian yang didukung oleh Sambelay et al., (2017) yang menunjukkan bahwa ROA berpengaruh terhadap harga saham.

Debt to Equity Ratio (DER) merupakan perbandingan antara hutang baik jangka pendek maupun jangka panjang terhadap modal sendiri yang dimiliki perusahaan. Berdasarkan signalling theory angka rasio DER dapat memberi sinyal yang berupa kabar buruk karena investor beranggapan bahwa perusahaan tersebut memiliki banyak risiko sehingga investor akan bereaksi dengan menghindari membeli saham perusahaan ketika rasio DER yang tinggi. Hal tersebut didukung oleh hasil penelitian Khairudin \& Wandita (2017), Ratih (2013) yang menyatakan bahwa Debt to Equity Ratio (DER) berpengaruh terhadap harga saham.

Earning per Share (EPS) merupakan kemampuan perusahaan untuk mendistribusikan pendapatannya kepada para pemegang saham. Signalling theory menunjukkan jumlah EPS yang ditujukan perusahaan dalam laporan keuangan dapat memberikan sinyal baik kepada investor. Ketika EPS suatu perusahaan tinggi maka permintaan terhadap saham akan meningkat, maka harga saham perusahaan itu akan meningkat juga. Hal ini sejalan dengan penilitian yang dilakukan oleh Khairudin \& Wandita (2017), Ratih (2013), Egam et al., (2017) serta Amanda et al ., (2013).

Dari penelitian-penelitian terdahulu di atas, terdapat 3 hipotesis alternatif penelitian:

H1 : Return on Asset berpengaruh terhadap harga saham pada perusahaan pertambangan (sektor industri batubara) yang terdaftar di Bursa Efek Indonesia (BEI) pada tahun 20162018.

H2: Debt to Equity berpengaruh terhadap harga saham pada perusahaan pertambangan (sektor industri batubara) yang terdaftar di Bursa Efek Indonesia (BEI) pada tahun 20162018.

H3 : Earning per Share berpengaruh terhadap harga saham pada perusahaan pertambangan (sektor industri batubara) yang terdaftar di Bursa Efek Indonesia (BEI) pada tahun 20162018.

\section{METODOLOGI PENELITIAN}

Sumber data penelitian ini adalah bersumber dari website www.idx.co.id dan riset kepustakaan. Data tersebut berupa data sekunder dengan populasi sampel sebanyak 23 perusahaan yang telah sesuai kriteria yang bergerak dalam industri pertambangan batubara serta terdaftar di Bursa Efek Indonesia untuk periode 2016-2018. 
Dari data yang dikumpulkan tersebut dipilih data terkait variabel harga saham (Y) sebagai variabel terikat dan ROA (X1), DER (X2) dan EPS(X3) sebagai variabel bebas. Secara statistik persamaan dari semua variabel dapat dituliskan sebagai berikut :

Dimana :

$$
\mathrm{HS}=\mathrm{a}+\beta \mathrm{ROA}+\beta \mathrm{DER}+\beta \mathrm{EPS}+\mathrm{e}
$$

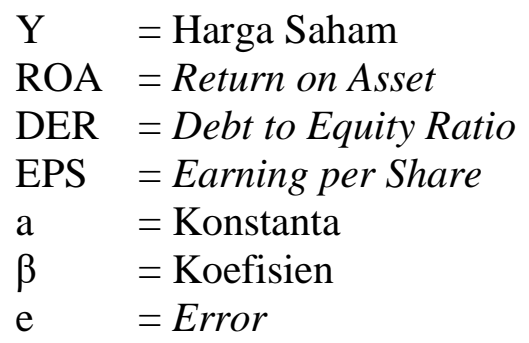

\section{HASIL DAN PEMBAHASAN}

Berdasarkan hasil penelitian diperoleh model persamaan sebagai berikut :

\section{HS = 2004,79 +864,35 ROA + 5,33 DER + 3,33 EPS}

Dari persamaan di atas dapat diperhatikan bahwa nilai konstanta yang menjadi koefisien model regresi sebesar 2004,79. Hal ini berarti jika tidak ada perubahan variabel ROA, DER, dan EPS tetap sebesar 2004,79.

Nilai koefisien regresi ROA diperoleh sebesar 864,35. Hal ini berarti bahwa apabila ROA bertambah $1 \%$ maka akan menaikkan harga saham sebesar 864,35\%. Nilai koefisien regresi DER diperoleh sebesar 5,33. Hal ini berarti bahwa DER bertambah 1\% maka akan menaikkan harga saham sebesar 5,33\%. Nilai koefisien regresi EPS diperoleh sebesar 3,33\%. Hal ini berarti bahwa apabila EPS bertambah 1\% maka akan menaikkan harga saham sebesar 3,33\%.

\section{Tabel 1}

Uji Chow

$\begin{array}{lrrc}\text { Effects Test } & \text { Statistic } & \text { d.f. } & \text { Prob. } \\ \text { Cross-section F } & 3.068221 & (22,43) & 0.0008 \\ \text { Cross-section Chi-square } & 65.123802 & 22 & 0.0000\end{array}$

Berdasarkan tabel 1 diatas terlihat bahwa probabilitas cross-section Chi-Square sebesar $0,0000<0,05$. Probabilitas cross-section $F$ sebesar 0,0008 <0,05. Hasil uji chow tersebut dapat disimpulkan bahwa model penelitian akan menggunakan model Fixed Effect Model (FEM) maka selanjutnya akan dilakukan uji hausman.

\section{Tabel 2}

\section{Uji Hausman}

$\begin{aligned} & \text { Correlated Random Effects - Hausman Test } \\
& \text { Equation: Untitled }\end{aligned}$
\begin{tabular}{lrrr}
\hline Test cross-section random effects & & & \\
\hline & Chi-Sq. & & \\
Test Summary & Statistic & Chi-Sq. d.f. & Prob. \\
\hline \hline Cross-section random & 35.471756 & 3 & 0.0000
\end{tabular}

Berdasarkan tabel 2 diatas besarnya probabilitas cross-section random sebesar 0,0000. Nilai probabilitas cross-section random tersebut $<0,05$, maka hasil hausman test menunjukkan bahwa model Fixed Effect Model (FEM) lebih tepat digunakan untuk model persamaan regresi pada penelitian ini. 


\begin{tabular}{|c|c|c|c|c|}
\hline \multicolumn{5}{|c|}{$\begin{array}{l}\text { Hasil Output Fixed } \\
\text { Dependent Variable: HARGA_SAHAM } \\
\text { Method: Panel Least Squares } \\
\text { Date: 05/17/20 Time: 03:13 } \\
\text { Sample: 2016 2018 } \\
\text { Periods included: } 3 \\
\text { Cross-sections included: } 23 \\
\text { Total panel (balanced) observations: } 69\end{array}$} \\
\hline Variable & Coefficient & Std. Error & t-Statistic & Prob. \\
\hline $\begin{array}{c}\text { C } \\
\text { ROA } \\
\text { DER } \\
\text { EPS }\end{array}$ & $\begin{array}{l}2004.794 \\
864.3456 \\
5.331366 \\
3.331514\end{array}$ & $\begin{array}{l}394.6866 \\
4333.703 \\
72.18242 \\
0.801605\end{array}$ & $\begin{array}{l}5.079457 \\
0.199447 \\
0.073860 \\
4.156055\end{array}$ & $\begin{array}{l}0.0000 \\
0.8429 \\
0.9415 \\
0.0002\end{array}$ \\
\hline \multicolumn{5}{|c|}{ Effects Specification } \\
\hline \multicolumn{5}{|c|}{ Cross-section fixed (dummy variables) } \\
\hline $\begin{array}{l}\text { R-squared } \\
\text { Adjusted R-squared } \\
\text { S.E. of regression } \\
\text { Sum squared resid } \\
\text { Log likelihood } \\
\text { F-statistic } \\
\text { Prob(F-statistic) }\end{array}$ & $\begin{array}{r}0.938353 \\
0.902512 \\
1818.281 \\
1.42 \mathrm{E}+08 \\
-599.4811 \\
26.18077 \\
0.000000\end{array}$ & $\begin{array}{l}\text { an depende } \\
\text { dependen } \\
\text { aike info cri } \\
\text { warz criter } \\
\text { inan-Quinn } \\
\text { bin-Watsor }\end{array}$ & & $\begin{array}{l}3355.739 \\
5823.507 \\
18.12989 \\
18.97172 \\
18.46387 \\
3.574303\end{array}$ \\
\hline
\end{tabular}

\section{Sumber : data diolah dari Eviews 9}

Berdasarkan tabel 3 menunjukkan bahwa variabel ukuran ROA mempunyai taraf signifikansi sebesar 0,8429 dan nilai thitung sebesar 0,199447. Nilai signifikansi ini berada diatas alfa penelitian yaitu 0,05 , sehingga diinterpretasikan bahwa variabel ROA tidak mempunyai pengaruh signifikan terhadap harga saham perusahaan pertambangan batubara. Hal ini berarti perusahaan yang memiliki ROA tinggi maupun rendah belum tentu memiliki harga saham yang tinggi ataupun rendah juga. Bagi investor ROA akan sebagai salah satu pertimbangannya dalam mengambil keputusan investasinya.

Tabel 3 juga menunjukkan bahwa variabel DER mempunyai taraf signifikansi sebesar

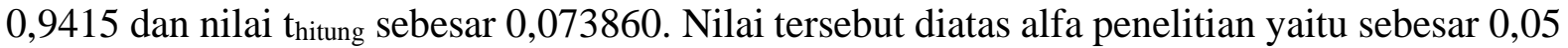
sehingga dapat diinterpretasikan bahwa variabel DER tidak mempunyai pengaruh signifikan terhadap harga saham perusahaan pertambangan batubara. Hal ini berarti besar kecilnya DER dalam perusahaan belum dapat mempengaruhi tinggi rendahnya harga saham suatu perusahaan. Investor biasanya akan melihat dari seberapa besar perusahaan mampu memanfaatkan hutangnya untuk biaya operasional perusahaan tersebut, jika berhasil memanfaatkannya maka akan memberikan sinyal positif bagi investor untuk menanamkan modalnya pada perusahaan tersebut dan harga saham akan naik. Sebaliknya jika perusahaan gagal dalam memanfaatkan hutangnya maka akan memberikan sinyal negatif bagi investor.

Variabel EPS diduga merupakan variabel yang mempunyai harga saham. Pada tabel 3 variabel ini mempunyai taraf signifikansi 0,0002 dan nilai $t_{\text {hitung }}$ sebesar 4,156055 . Nilai tersebut dibawah alfa penelitian yaitu sebesar 0,05 sehingga dapat diinterpretasikan bahwa variabel EPS mempunyai pengaruh signifikan terhadap harga saham perusahaan pertambangan batubara. EPS perusahaan dapat memberikan signal yang baik bagi investor. EPS yang besar menandakan bahwa kemampuan perusahaan yang lebih besar dalam menghasilkan keuntungan bersih dari setiap lembar saham. Oleh karena itu, semakin tinggi EPS akan semakin menarik minat investor dalam menanamkan modalnya. 
Pada tabel 1 dengan signifikansi 5\% dan derajat kebebasan df1=3 dan df2=69 maka didapatkan $\mathrm{F}_{\text {tabel }}=2,74$. Maka diperoleh perhitungan nilai $\mathrm{F}_{\text {hitung }}$ lebih besar dari $\mathrm{F}_{\text {tabel }}$ yaitu 26,18077 > 2,74 sehingga $\mathrm{H}_{0}$ ditolak. Sedangkan Nilai $p$-value ROA, DER, dan EPS diperoleh nilai $p$-value sebesar 0,000 . Nilai tersebut $<0,05$ maka $\mathrm{H}_{\mathrm{a}}$ diterima. Artinya hal ini menunjukkan bahwa secara simultan terdapat pengaruh ROA, DER, dan EPS terhadap harga saham pada perusahaan pertambangan (sektor industri batubara) yang terdaftar di Bursa Efek Indonesia tahun 2016-2018.

Koefisien determinasi $\left(\mathrm{R}^{2}\right)$ bertujuan untuk mengukur seberapa jauh kemampuan model dalam menerangkan variasi variabel dependen (harga saham). Nilai tersebut adalah antara nol dan satu. Nilai $\mathrm{R}^{2}$ yang kecil berarti kemampuan variabel-variabel independen (ROA,DER, dan

EPS) dalam menjelaskan variasi variabel dependen amat terbatas dan sebaliknya.

Pada tabel 1 dari hasil regresi data panel terlihat dari Adjusted $R$ Square sebesar 0,902512. Hal ini berarti bahwa ada kontribusi ROA, DER, dan EPS sebesar 90,25\% dalam memprediksi harga saham secara bersama-sama, sedangkan $9,75 \%$ dijelaskan oleh faktorfaktor lain diluar variabel yang diteliti.

\section{KESIMPULAN}

Penelitian ini memperoleh bahwa Earning per Share (EPS) secara parsial memiliki pengaruh signifikan terhadap harga saham. Sedangkan Return on Asset (ROA) dan Debt to Equity Ratio (DER) secara parsial tidak memiliki pengaruh signifikan terhadap harga saham. Secara bersama-sama juga ditemukan bahwa ROA, DER, dan EPS memiliki pengaruh signifikan terhadap harga saham perusahaan pertambangan (sektor industri batubara) yang terdaftar di Bursa Efek Indonesia selama periode 2016-2018.

Penelitian ini memiliki keterbatasan penelitian yang dapat dijadikan bahan pertimbangan untuk melakukan penelitian selanjutnya yaitu keterbatasan dalam menggunakan rasio keuangan yang hanya diwakili oleh 3 rasio yaitu ROA,DER dan EPS. Serta periode penelitian yang cukup pendek hanya 3 tahun.

Berdasarkan penelitian ini maka penulis memberikan saran agar penelitian selanjutnya dapat memperluas populasi penelitian, menambahkan periode pengamatan dan juga memasukkan variabel independen lain.

\section{DAFTAR PUSTAKA}

Amanda, A., Darminto, \& Husaini, A. (2013). Pengaruh Debt to Equity Ratio, Return on Equity, Earning per Share, dan Price Earning Ratio terhadap Harga Saham. Jurnal Akuntansi, 4 (2), 1-11.

Atidhira, A. T., \& Yustina, A. I. (2017). The Influence of Return on Asset, Debt to Equity Ratio, Earning per Share, and Company Size on Share Return in Property and Real Estate Companies. Journal of Applied Accounting and Finance, 1 (2), 128-146.

Egam, G. E., Ilat, V., \& Pangerapan, S. (2017). Pengaruh Return on Asset (ROA), Return on Equity (ROE), Net Profit Margin (NPM), dan Earning per Share (EPS) terhadap Harga Saham Perusahaan yang Tergabung dalam Indeks LQ45 di Bursa Efek Indonesia Periode Tahun 2013-2015. Jurnal EMBA, 5 (1), 105-114.

Idawati, W., \& Wahyudi, A. (2015). Effect of Earning per Share (EPS) and Return on Asset (ROA) Against Share Price on Coal Mining Company Listed in Indonesia Stock Exchange. Journal of Resources Development and Management, 7, 79-91.

Khairudin, \& Wandita. (2017). Analisis Pengaruh Rasio Profitabilitas, Debt to Equity Ratio (DER) dan Price Book Value (PBV) Terhadap Harga Saham Perusahaan Pertambangan di Indonesia. Jurnal Akuntasi \& Keuangan, 8 (1), 68-84.

Megawati, S. B. (2018). Pengaruh Rasio Keuangan terhadap Harga Saham pada Perusahaan Telekomunikasi yang Terdaftar di Bursa Efek Indonesia Tahun 2012-2016. Jurnal Pendidikan dan Ekonomi, 7 (5), 418-429. 
Putri, L. P. (2015). Pengaruh Profitabilitas terhadap Harga Saham pada Perusahaan Pertambangan Batubara di Indonesia. Jurnal Ilmiah Manajemen dan Bisnis, 16 (2), 4959.

Ramadhan, A. V., \& Adrianto, F. (2019). Pengaruh Analisis Fundamental terhadap Return Saham, Analisa Komparasi Perbandingan Bank pada Bank Umum Kegiatan Umum (BUKU) 3\&4 dan Buku 1\&2 di Indonesia. Jurnal Ilmiah Mahasiswa Ekonomi Manajemen, 4 (1), 413-426.

Ratih, D., Prihatini, A. E., \& Saryadi. (2013). Pengaruh EPS, PER, DER, ROE terhadap Harga Saham Pada Perusahaan Sektor Pertambangan yang Terdaftar di Bursa Efek Indonesia (BEI) Tahun 2010-2012. Journal Ilmu Administrasi Bisnis, 3 (1), 1-12.

Sahebuan, D., Yuhelmi, \& Dharma, S. (2014). Pengaruh ROA, ROE, EPS dan Investasi terhadap Harga Saham pada Perusahaan yang Melakukan Dividend Cut dan Tidak Dividend Cut (Perusahaan yang Terdaftar di BEI Periode 2008-2012). Jurnal Fakultas Ekonomi, 5 (2), 1-13.

Sambelay, J. J., Rate, P. V., \& Baramuli, D. N. (2017). Analisis Pengaruh Profitabilitas terhadap Harga Saham pada Perusahaan yang Terdaftar di LQ45 Periode 2012-2016. Jurnal EMBA, 5 (2), 753-761.

Sari, N. M., \& Triartyati, N. (2015). Analisis Pengaruh Profitabilitas, EPS, dan PER terhadap Harga Saham Perusahaan Perbankan di BEI sebagai Dasar Pengambilan Keputusan Investasi. E-Jurnal Manajemen, 4 (3), 575-589.

Situmorang, J., Lau, E. A., \& Masithoh, R. (2016). Aktor Penentu Harga Saham Pertambangan Subsektor Batubara yang Terdaftar di Bursa Efek Indonesia (BEI). Jurnal Ekonomi, 5 (1), 29-42.

Utami, M. R., \& Darmawan, A. (2018). Pengaruh DER, ROA, ROE, EPS dan MVA terhadap Harga Saham pada Indeks Saham Syariah Indonesia. Journal of Applied Managerial Accounting, 2 (2), 77-89.

Wicaksono, R. B. (2015). Pengaruh EPS, PER, DER, ROE dan MVA terhadap Harga Saham. Jurnal Akuntansi.

Widayanti, R., Ekawati, H., Atahau, A. D., Rita, M. R., \& Sucahyo, U. S. (2009). Manajemen Keuangan. Salatiga : Fakultas Ekonomi Universitas Kristen Satya Wacana. 